\title{
Human Cells, Tissues, and Cellular and Tissue-Based Products Communicable Disease Testing
}

National Cancer Institute

\section{Source}

National Cancer Institute. Human Cells, Tissues, and Cellular and Tissue-Based Products Communicable Disease Testing. NCI Thesaurus. Code C133283.

Testing Human Cells, T issues, and Cellular and T issue-Based Products (HCT/Ps) donors for infectious diseases. 